\title{
Small leucine-rich proteoglycans (SLRPs) in uterine tissues during pregnancy in mice
}

\author{
S. San Martin¹, M. Soto-Suazo ${ }^{1,2}$, S. Ferreira de Oliveira1 ${ }^{1}$ J. D. Aplin³, \\ P. Abrahamsohn ${ }^{1}$ and T. M. T. Zorn ${ }^{1 *}$ \\ ${ }^{1}$ Laboratory of Biology of Reproduction, Department of Histology and Embryology, Institute \\ of Biomedical Sciences, University of São Paulo, São Paulo 05508-900, Brazil; ${ }^{2}$ School of Medicine, \\ Faculty of Medical Sciences, University of Santiago de Chile, Casilla 112, Chile; and ${ }^{3}$ Medical School \\ and School of Biological Sciences, University of Manchester, Manchester M13 9PT, UK
}

\begin{abstract}
Remodelling of the extracellular matrix (ECM) occurs during decidualization of the endometrium in mice. Previously we have documented the appearance of largediameter collagen fibrils around mature decidual cells between day 5 and day 7 of pregnancy. Proteoglycans are important in the regulation of collagen fibrillogenesis, and the present study analysed four members (decorin, biglycan, lumican and fibromodulin) of the family of small leucine-rich proteoglycans (SLRPs) in the uterus from day 1 to day 7 of pregnancy. Decorin was present together with lesser amounts of lumican in the stroma before the onset of decidualization, whereas biglycan and fibromodulin were almost absent. Biglycan and, less significantly, lumican were expressed in decidualized regions of the
\end{abstract}

endometrium, but decorin was absent. Fibromodulin was weakly expressed in the non-decidualized stroma, but only after implantation. Decorin and lumican were strongly expressed in the undifferentiated interimplantation site stroma, whereas biglycan and fibromodulin were expressed only weakly. These results indicate that the SLRP profile of the uterine ECM alters with differentiation of endometrial stromal cells. The large decidual collagen fibrils are thought to arise by lateral association of smaller diameter fibrils. As decorin has been shown to inhibit lateral association of collagen fibrils, its disappearance between day 2 and day 5 of pregnancy may be a prerequisite for the formation of large fibrils in decidua in mice.

\section{Introduction}

Decorin, biglycan, fibromodulin and lumican are members of a family of small leucine-rich proteoglycans (SLRPs) of the extracellular matrix (ECM) (Hocking et al., 1998; Iozzo, 1999). They share structural similarities; of the three main structural domains, the $\mathrm{N}$-terminal domains are least similar, though all members contain four conserved cysteine residues. This domain is frequently substituted with chondroitin or dermatan sulphate chains, as in decorin (Krusius and Ruoslahti, 1986) and biglycan (Fisher et al., 1989), or with keratan sulphate in fibromodulin (Antonsson et al., 1991) and lumican (Scott, 1996). The most pronounced sequence similarity is in the central domains, which constitute $60-80 \%$ of the total amino acid residues including ten repeats of a leucine- and asparagine-rich motif (Antonsson et al., 1991; Blochberger et al., 1992; Dunlevy et al., 1998). The C-terminal domains contain two cysteine residues that form an intrachain disulphide bond.

\footnotetext{
*Correspondence

Email: temtzorn@usp.br
}

The interaction of proteoglycans with collagen fibrils is important in the assembly and maintenance of the ECM during growth and development (lozzo, 1997; Hocking et al., 1998). There are indications that decorin, fibromodulin and lumican bind to fibrillar collagens, leading to delayed fibril formation and the formation of thinner fibrils (Vogel et al., 1984; Vogel and Trotter, 1987; Hedbom and Heinegard, 1989; Rada et al., 1993; Ezura et al., 2000). A horseshoe-shaped conformation lends itself to binding to specific sites on the fibril (Scott, 1996; lozzo, 1999). Gene ablation experiments have demonstrated that mice lacking these SLRPs have abnormalities of collagen fibrillogenesis leading to fragile skin, corneal opacity, osteoporosis or osteoarthritis (Danielson et al., 1997; Chakravarti et al., 1998; Xu et al., 1998; Svensson et al., 1999; Ameye et al., 2002). There is evidence that both decorin and biglycan are involved in the binding of transforming growth factor $\beta$ (TGF- $\beta$ ) and modulation of its activity, and this may account for aspects of the respective null phenotypes (Hausser et al., 1994; Lysiak et al., 1995; De Luca et al., 1996; Kolb et al., 2001; Schaefer et al., 2002). In addition, decorin is capable of directly suppressing cell proliferation (Santra et al., 1997; Mosacatello et al., 1998). 

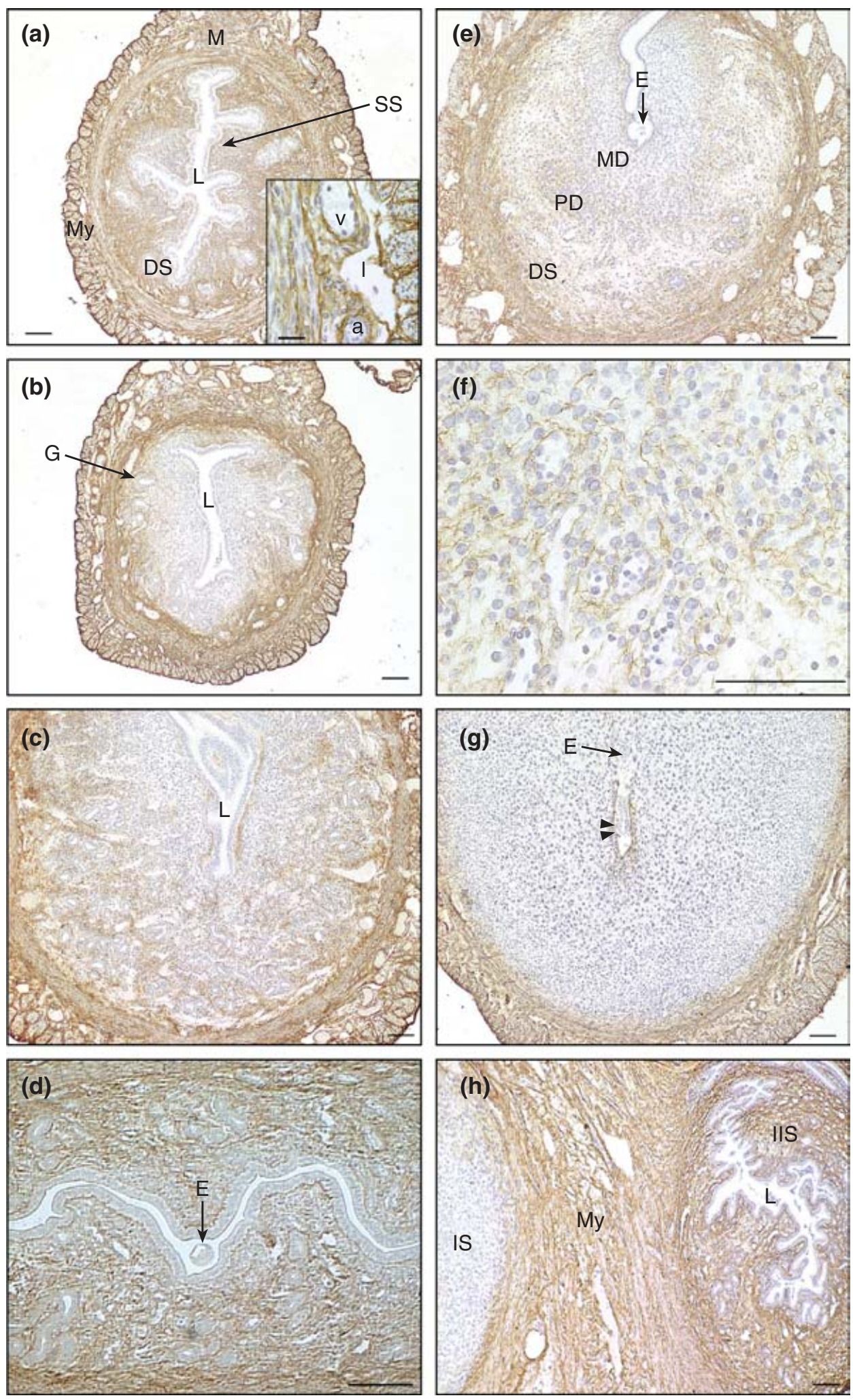

Fig. 1. For legend see facing page. 
The endometrial stroma undergoes a remarkable reorganization during early pregnancy in mice. Proliferation, rearrangement, enlargement and secretory differentiation of fibroblasts are accompanied by recruitment of specific immune cell populations and alterations in the shape of the uterine lumen (De Feo, 1967; Finn and McLaren, 1967; Reinius, 1967; Zorn et al., 1986; Bijovsky et al., 1992; Abrahamsohn and Zorn, 1993; Tenório and Zorn, 1998; Abrahamsohn, 2002; Tong and Pollard, 2002). These changes require exposure to a defined hormonal regimen, followed by a triggering stimulus normally provided by the implanting embryo (Finn, 1977; Parr and Parr, 1989; Abrahamsohn and Zorn, 1993).

Decidualization in rodents and humans also requires remodelling of stromal ECM with degradation and de novo synthesis of collagens, and alterations to noncollagenous components (Zorn et al., 1986; Aplin et al., 1988; Alberto-Rincon et al., 1989; Aplin and Jones, 1989; Mulholland et al., 1992; Mylona et al., 1995; Oliveira et al., 1995; Church et al., 1996; Aplin, 2002). The increase in mean collagen fibril diameter is particularly notable in the endometrium in pregnant mice (Zorn et al., 1986). Very thick collagen fibrils appear in decidualized regions, but are absent from the nondecidualized stroma as well as from interimplantation site regions (Alberto-Rincon et al., 1989). Ultrastructural cytochemical observations reveal differences in the arrangement and distribution of proteoglycans between different regions of the endometrium in pregnant mice (Greca et al., 1998). Moreover, thick collagen fibrils are associated with proteoglycans containing chondroitin sulphate and dermatan sulphate chains. The possibility that SLRPs could be associated with the thick collagen fibrils (Greca et al., 2000) stimulated the present investigation of the distribution of four different SLRP family members during the first week of pregnancy in the uterus in mice.

\section{Materials and Methods}

\section{Tissue collection}

Swiss female mice aged 2-3 months were housed in a $12 \mathrm{~h}$ light: $12 \mathrm{~h}$ dark schedule at $22^{\circ} \mathrm{C}$, with food and water available at all times. The mice were mated and were examined for copulation plugs each morning. The day on which a vaginal plug was observed was considered as day 1 of pregnancy. At least three pregnant animals each on days 1, 2, 3, 4, 5, 6 and 7 were anaesthetized with an i.p. injection of avertin $(0.025 \mathrm{ml}$ $\mathrm{g}^{-1}$ body weight), then killed by cervical dislocation, and both uterine horns were excised and dissected free of fat. Animals on day 5 of pregnancy were injected with $0.15 \mathrm{ml}$ of a solution of $0.25 \%(\mathrm{w} / \mathrm{v})$ Evans blue through a tail vein, 20 min before killing, in order to detect the implantation sites (Psychoyos, 1960; Finn and McLaren, 1967). National principles of laboratory animal care were followed and the experiments were approved by the Institute of Biomedical Sciences Animal Ethics Committee (authorization number 107/2000).

\section{Immunoperoxidase staining}

Implantation sites were fixed for $3 \mathrm{~h}$ in methacarn (absolute methanol, chloroform, glacial acetic acid; $6: 3: 1$ ), rinsed with absolute ethanol and embedded in Paraplast (Oxford, St Louis, MO) at $60^{\circ} \mathrm{C}$. Sections $(5 \mu \mathrm{m}$ thick) were cut and adhered to glass slides using $0.1 \%$ poly-L-lysine (Sigma, St Louis, MO) and then dried at room temperature $\left(25^{\circ} \mathrm{C}\right)$. Each of the succeeding steps was followed by a thorough rinse with PBS.

Sections were treated with $3 \%(\mathrm{v} / \mathrm{v}) \mathrm{H}_{2} \mathrm{O}_{2}$ in PBS for $30 \mathrm{~min}$ to block endogenous peroxidase activity. All steps were performed in a humid chamber and care was taken to avoid drying out of sections. Sections were incubated for $1 \mathrm{~h}$ at $37^{\circ} \mathrm{C}$ in $20 \mathrm{mmol}$ Tris- $\mathrm{HCl}$ $\mathrm{I}^{-1}\left(\mathrm{pH}\right.$ 6.0) containing $0.2 \mathrm{U}$ chondroitinase $\mathrm{ABC} \mathrm{\textrm {ml } ^ { - 1 }}$ (Seikagaku Corp., Tokyo) before the immunoreaction for decorin and biglycan. Non-specific staining was blocked by incubating the sections for $30 \mathrm{~min}$ with normal goat serum diluted $1: 1$ in PBS-10\% (v/v) BSA.

Rabbit polyclonal antibodies raised against murine decorin (LF-113), biglycan (LF-106) (Fisher et al., 1995), fibromodulin and lumican (Svensson et al., 1999) were diluted $1: 2000,1: 1000,1: 400$ and $1: 800$ respectively, in PBS- $-0.3 \%(\mathrm{v} / \mathrm{v})$ Tween 20 , and incubated overnight at $4{ }^{\circ} \mathrm{C}$. The sections were washed thoroughly with PBS

Fig. 1. Immunoperoxidase localization of decorin in the uterus in mice. (a) Day 1 of pregnancy. Decorin is equally distributed in both superficial (SS) and deep endometrial stroma (DS) as well as in the myometrium (My). Inset: high magnification image showing decorin surrounding a venule (v), a lymphatic vessel (I) and an arteriole (a). Scale bar represents $25 \mu \mathrm{m}$. (b) Day 2 of pregnancy. Decorin is restricted to the deep stroma and myometrium. (c) Day 3 of pregnancy. Similar to the previous day, decorin is present mainly in the deep stroma, surrounding uterine glands $(\mathrm{G})$ and in the myometrium. (d) Longitudinal section of a uterine horn on day 4 of pregnancy. Decorin is observed in both superficial and deep stroma and in the myometrium. (e) Day 5 day of pregnancy. A weak reaction for decorin is observed in the region of predecidua (PD). Strong reaction for decorin, however, is observed in the region of deep stroma and myometrium. (f) High magnification showing decorin-positive fibrils between predecidual cells at day 5. (g) Day 7 of pregnancy. Reaction for decorin is observed in the region of the deep stroma and myometrium and as delicate fibrils surrounding the implantation crypt (arrowhead). (h) Longitudinal section of a uterine horn on day 7 of pregnancy. On the left is part of an implantation site (IS) from which decorin is completely absent. On the right is interimplantation site (IIS) tissue showing a strong reaction for decorin in the endometrial stroma as well as in the myometrium. E: embryo; L: uterine lumen; M: mesometrium; MD: mature decidua. Scale bars represent $100 \mu \mathrm{m}$. 

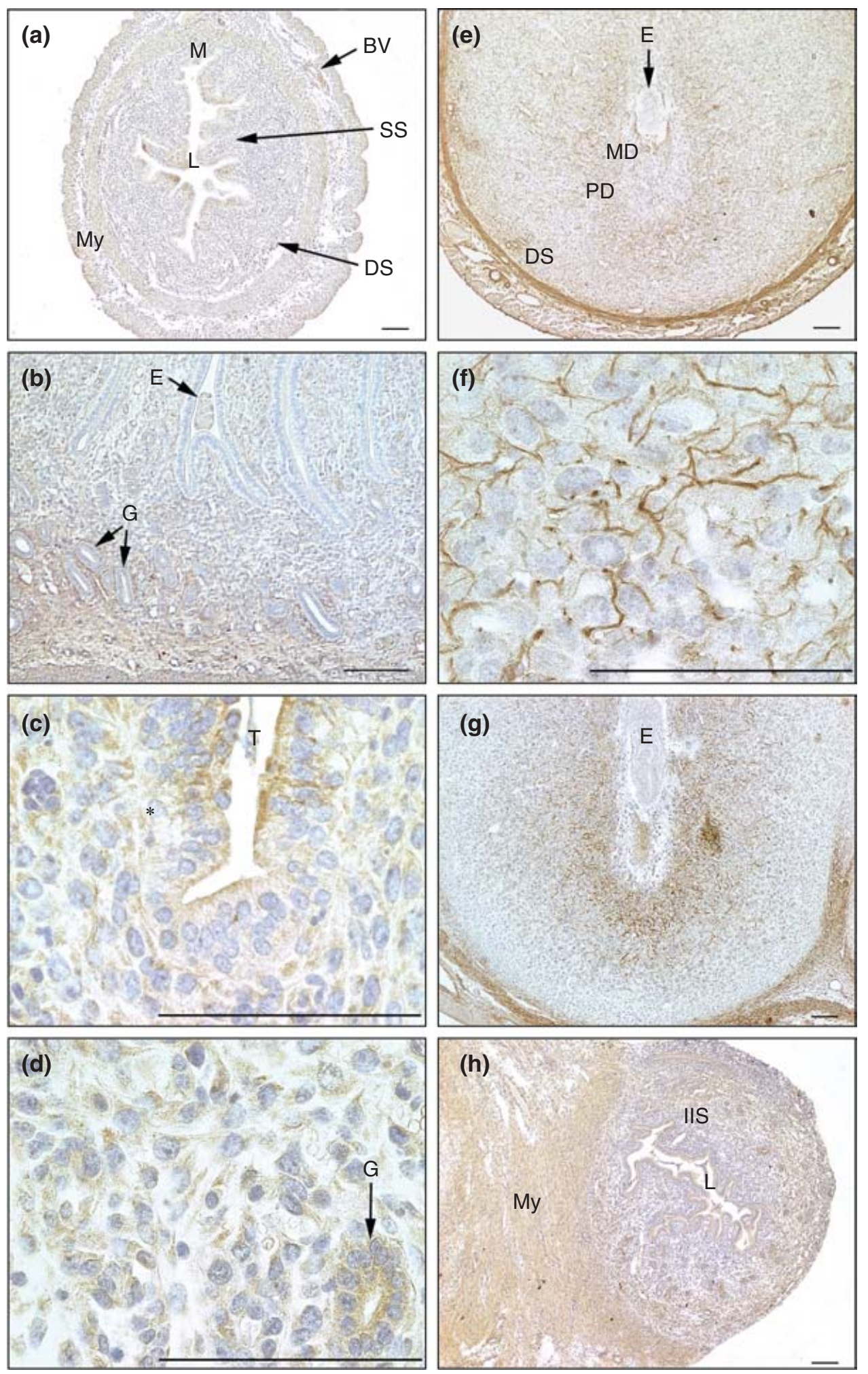

Fig. 2. For legend see facing page. 
followed by incubation with biotin-conjugated goat antirabbit IgG (Vector Labs, Burlingame, CA; 1 : 1000 in PBS, $1 \mathrm{~h}$ at room temperature). After rinsing three times in PBS, sections were incubated in streptavidin-peroxidase complex (Vector) for $1 \mathrm{~h}$ at room temperature.

Peroxidase was visualized using $0.03 \%(\mathrm{w} / \mathrm{v}) 3,3^{\prime}-$ diaminobenzidine in PBS with $0.03 \%(\mathrm{v} / \mathrm{v}) \mathrm{H}_{2} \mathrm{O}_{2}$. The sections were counterstained with Mayer's haematoxylin. The specificity of immunolabelling was tested by omitting the primary antibody or the use of other primary rabbit sera. Sections of trachea were used as positive controls. A Nikon Eclipse E600 microscope was used for examining sections. Images were captured using a digital camera (COOL SNAP-PROcf color) and Image Pro Plus software (Media Cybernetics, Silver Spring, MD).

\section{Results}

\section{Decorin: preimplantation period}

Decorin was present in the myometrium from day 1 to day 4 of pregnancy (Fig. 1a-d) as well as in the basement membranes of blood vessels, particularly those situated in the connective tissue of the myometrium and mesometrium (Fig. 1a). A weak reaction was observed surrounding uterine glands particularly during days 1 and 2 of pregnancy (Fig. 1a,b). However, staining with decorin in the endometrial stroma changed according to the day of pregnancy. On day 1, most of the endometrial stroma was immunoreactive except for a small subepithelial area (Fig. 1a). On day 2, decorin almost disappeared from the superficial stroma and became restricted to the deep stroma (Fig. 1b). A similar distribution was maintained on day 3 (Fig. 1c). However, on day 4 of pregnancy, decorin was present again in the superficial stroma as observed on day 1 (Fig. 1d).

\section{Decorin: postimplantation period}

On day 5 of pregnancy, decorin was clearly diminished in the area occupied by the decidualized cells surrounding the implantation crypt, but in other regions of the uterus the distribution was similar to that of previous days (Fig. 1e). Decorin was associated with scattered thin intercellular fibrils in the region of predecidual cells (Fig. 1f) and was observed as a network of thin fibrils surrounding endometrial fibroblasts, glands and blood vessels in the nondecidualized basal stroma near the myometrial junction (Fig. 1e).

On days 6 and 7, the immunoreaction for decorin almost disappeared from both mature and predecidual regions. On these days, only rare positive fibrils were observed between cells at the end of the implantation crypt (Fig. 1g). In the deep stroma, the reaction was also clearly diminished when compared with day 5 and was restricted to a narrow region close to the myometrium. However, in the myometrium and mesometrium, the reaction was similar to the previous days. In contrast to the implantation sites, the reaction for decorin was very strong in the interimplantation sites where decorin was broadly distributed throughout the endometrial stroma. A strong reaction was also present in the myometrium (Fig. 1h).

\section{Biglycan: preimplantation period}

Immunoreaction for biglycan was not detected in the endometrial stroma during days 1 (Fig. 2a), 2 and 3 of pregnancy (not shown). During these days, a weak reaction for biglycan was restricted to areas surrounding small blood vessels of the myometrium. On day 4, however, a weak reaction was detectable in the ECM of the deep stroma, particularly surrounding uterine glands, as well as in the myometrium (Fig. 2b).

\section{Biglycan: postimplantation period}

Biglycan was present throughout the endometrial stroma during the postimplantation period (Fig. 2c,d). High magnification initially revealed that, unlike decorin, the immunoreaction for biglycan was predominantly concentrated in the cytoplasm of both decidualized and non-decidualized cells. Biglycan was also present in the cytoplasm of epithelial cells of the uterine lumen (Fig. 2c) and glands (Fig. 2d). By day 6, however, although some reactivity was maintained inside the cells, biglycan was

\footnotetext{
Fig. 2. Immunoperoxidase localization of biglycan in the uterus in mice. (a) Day 1 of pregnancy. Biglycan is almost absent from all regions. (b) Longitudinal section of a uterine horn on day 4 of pregnancy. Biglycan is restricted to the deep stroma (DS) surrounding the glands and myometrium (My). (c) Day 5 of pregnancy. Immunoreaction for biglycan is observed in the cytoplasm of mature decidual (MD) cells and in the apical cytoplasm of epithelial cells that line the uterine crypt $\left(^{*}\right)$. (d) Day 5 of pregnancy. Note the reaction for biglycan in the cytoplasm of predecidual cells and uterine glands. (e) Day 6 of pregnancy. Reaction for biglycan is observed in the region of predecidual (PD) cells and deep stroma as well as in the myometrium, but not in mature decidua. (f) High magnification of predecidual region showing biglycan-positive fibrils situated between the cells. (g) Longitudinal section of a uterine horn on day 7 of pregnancy. A strong reaction for biglycan is now observed, particularly in the region of mature decidual cells and myometrium. (h) Longitudinal section of an interimplantation site (IIS) which is almost negative for biglycan. BV: blood vessel; E: embryo; G: uterine glands; L: uterine lumen; M: mesometrium; SS: superficial endometrial stroma; T: trophoblast. Scale bars represent $100 \mu \mathrm{m}$.
} 
mostly observed as a fibrillar arrangement in the extracellular matrix, particularly in the region of predecidual cells (Fig. 2e,f). On day 7 the area of immunoreactivity was enlarged and seen mainly as fibrils between mature decidual cells (Fig. 2g). On this day, biglycan was weakly expressed in the deep stroma as well as around blood vessels of the mesometrial portion of the uterus. On both days 6 and 7, biglycan was present as a network of thin fibrils surrounding blood vessels at the periphery of the endometrium and in the connective tissues surrounding the muscular layers of the myometrium.

Biglycan was present in the interimplantation sites only at the periphery of the endometrial stroma and the pattern of reaction was very similar to that observed on day 4 of pregnancy. A weak reaction was also present in the myometrium (Fig. 2h).

\section{Lumican: preimplantation period}

On days 1, 2 (not shown) and 3 of pregnancy, lumican was weakly expressed in the subepithelial stroma, whereas a stronger immunoreaction was present in the deep stroma (Fig. 3a,b). On day 4 of pregnancy, lumican expression increased in the subepithelial stroma (Fig. 3c). Lumican was present in the connective tissue of the myometrium throughout preimplantation.

\section{Lumican: postimplantation period}

On days 5 (Fig. 3d,e), 6 and 7 of pregnancy (not shown), weak reaction for lumican was seen in both mature decidua and the predecidual region, whereas a strong reaction was observed in the non-decidualized region of the endometrium. During these days, lumican continued to be strongly detected in the connective tissue of the myometrium. In the interimplantation sites lumican was ubiquitously distributed (Fig. 3f).

\section{Fibromodulin: preimplantation period}

A reaction for fibromodulin was not detected in uterine tissues during the preimplantation period from day 1 (Fig. 4a) to day 4 (not shown). In contrast, a very strong immunoreaction was observed in the perichondrium of a tracheal cartilage used as positive control (Fig. 4f).

\section{Fibromodulin: periimplantation period}

From day 5 to day 7 , fibromodulin was absent in mature and predecidual regions, and was expressed weakly in the cytoplasm of fibroblasts of the deep endometrial stroma (Fig. 4b-d). Fibromodulin was observed surrounding blood vessels and also in the connective tissue and muscle cells of the myometrium, particularly in the antimesometrial region of the uterus. A reaction was not found in interimplantation site tissue (Fig. 4e).

\section{Discussion}

The results of the present study demonstrate complex spatiotemporal alterations of four SLRPs in the uterus during pregnancy in mice. Decorin and lumican are strongly expressed in the endometrium during the preimplantation period, whereas biglycan is weakly expressed and fibromodulin absent during the same period. At this time the stroma is undifferentiated. The loss of decorin from endometrial stroma precedes decidual differentiation. Lumican shows a similar pattern of alteration, with a lower abundance in decidua than in undifferentiated stroma. Biglycan appears initially during this period in the cytoplasm of stromal cells, and by day 6 has been secreted and integrated into ECM in decidualized areas. Thus, after implantation, only biglycan and lumican are present in the region of fully decidualized cells in which thick collagen fibrils accumulate. The consistent presence of decorin and lumican in interimplantation site stroma and in deeper areas of undifferentiated stroma beneath implantation sites confirms that the changes observed are locally stimulated. A distinctive response to pregnancy is observed in the myometrium, with decorin and lumican expressed throughout the period from day 1 to day 7 , whereas biglycan and fibromodulin appear only after implantation.

Loss of decorin, reduction in lumican and the appearance of biglycan all correlate with the loss of thin collagen fibrils and the appearance of thick fibrils in decidua (Zorn et al., 1986; Alberto-Rincon et al., 1989). Decidualization of the endometrium affects the regional organization of proteoglycans: ultrastructural cytochemical studies have demonstrated that the thick collagen fibrils present between decidual cells are associated with chondroitin sulphate and dermatan sulphate proteoglycans (Greca et al., 1998, 2000). The changing repertoire of SLRPs is likely to have a functional significance that is related to ECM remodelling. Collagen fibrillogenesis is a complex process involving lateral and axial growth, control of fibril diameter and interfibrillar spacing. Secretion of various types of collagen, enzymatic processing of the propeptides and association with glycosaminoglycans and proteoglycans are factors that are important in fibril assembly (Trelstad and Silver, 1981; Birk et al. 1990). Decorin (Vogel et al., 1984), fibromodulin (Hedbom and Heinegard, 1989) and lumican (Rada et al., 1993) have all been shown to bind to fibrillar collagens in vitro, leading to delayed fibril development and formation of thinner fibrils (Vogel and Trotter, 1987). This action is most likely caused by the binding of the SLRPs to the surface of axially growing fibrils (Kadler et al., 1996), inhibiting the incorporation of additional triple helical collagen monomers. Other studies, however, have indicated that the association of decorin with collagen produces thick collagen fibrils (Uldbjerg and Danielsen, 1988). These contradictory 

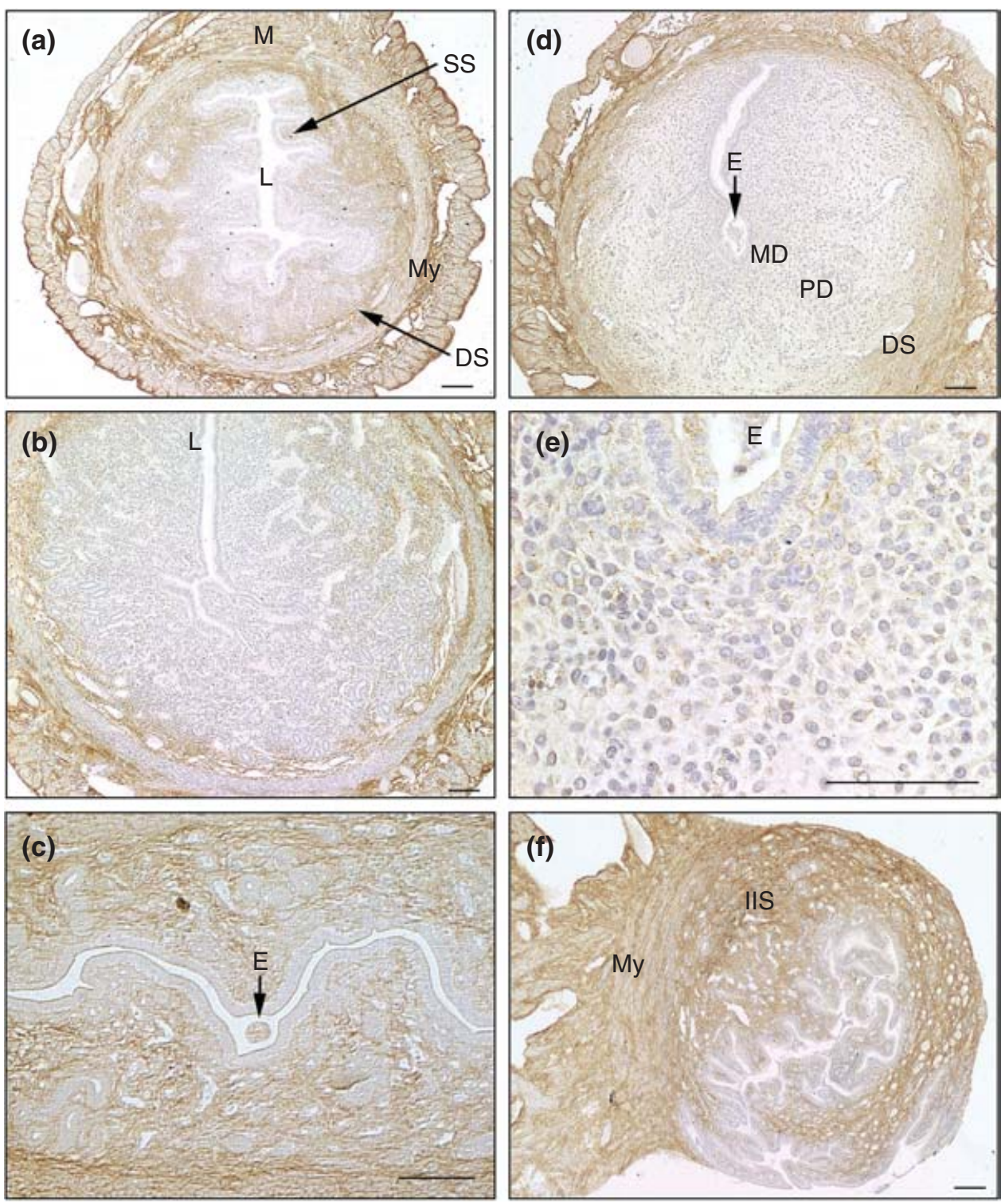

Fig. 3. Immunoperoxidase localization of lumican in the uterus in mice. (a) Day 1 of pregnancy. Lumican is weak in the superficial stroma (SS) and strong in deeper areas of stroma (DS). The connective tissue of myometrium (My) is strongly stained. (b) Day 3 of pregnancy. Lumican is observed in the deep stroma and in the connective tissue of the myometrium. (c) Longitudinal section of a uterine horn on day 4 of pregnancy. Lumican is present in both superficial and deep stroma and in the myometrium. (d) Day 5 of pregnancy. A weak reaction for lumican is observed in the region of mature decidual $(\mathrm{MD})$ cells and predecidua (PD). A stronger reaction is observed in the deep stroma and myometrium. (e) High magnification of mature decidual region showing a weak reaction between mature decidual cells. (f) Longitudinal section of an interimplantation site (IIS) on day 7 of pregnancy showing a strong reaction for lumican distributed in the entire endometrial stroma as well as in the myometrium. E: embryo; L: uterine lumen; M: mesometrium. Scale bars represent $100 \mu \mathrm{m}$.

data probably arise from the use of different experimental approaches by the various authors (Comper and Veis, 1977; Williams et al., 1978), but indicate the need to establish the mechanisms of fibril deposition and ECM remodelling in the uterus.
Biglycan may also affect fibrillogenesis of collagen. Studies by Schonherr et al. (1995) provide evidence for an interaction between biglycan and collagen I in vitro. Both decorin and biglycan decorate collagen II fibrils in human cartilage (Miosge et al., 1994). The loss of 

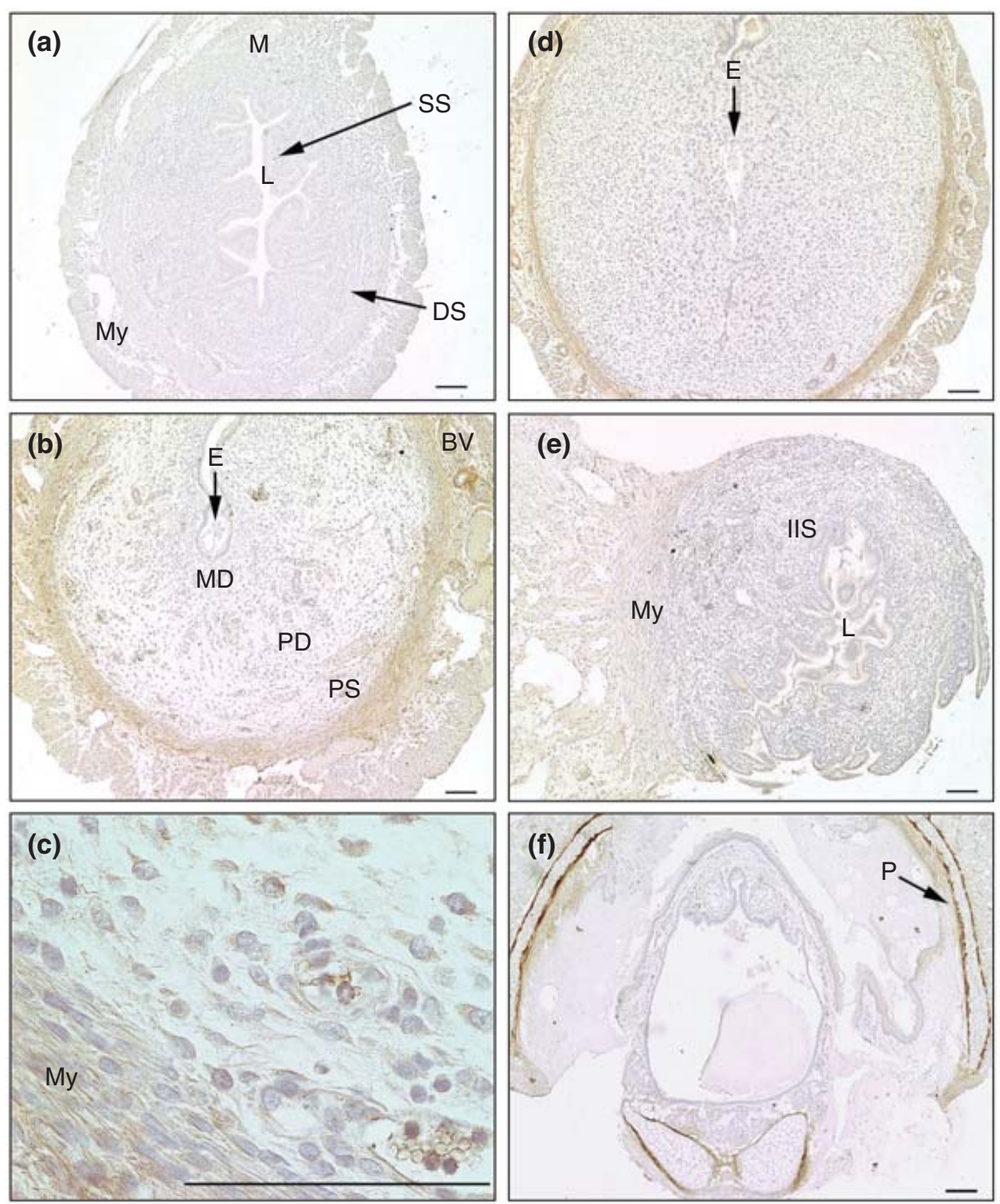

Fig. 4. Immunoperoxidase localization of fibromodulin in the uterus in mice. (a) Day 1 of pregnancy. Immunoreaction was not observed in any region. (b,c) Day 5 of pregnancy. Weak fibromodulin staining in the cytoplasm of fibroblasts of the deep stroma (DS) and in myometrium (My). (d) Day 6 of pregnancy. Immunoreaction for fibromodulin shows the same pattern as the previous day. (e) Longitudinal section of an interimplantation site (IIS) of a uterine horn on day 7 of pregnancy. Immunoreaction was not observed in the diverse uterine regions. (f) Section of trachea in mice showing a strong reaction for fibromodulin in the perichondrium (P). BV: blood vessel; E: embryo; $\mathrm{L}$ : uterine lumen; M: mesometrium; MD: mature decidua; PD: predecidual cells; SS: superficial endometrial stroma. Scale bars represent $100 \mu \mathrm{m}$.

decorin from regions in which thick collagen fibrils are developing (biglycan is expressed in the same regions) indicates that decorin may specifically inhibit fibril association, and that its disappearance may be a prerequisite for the formation of large fibrils in decidua. This finding is consistent with the expression of decorin but not biglycan in the interimplantation sites, where only thin collagen fibrils are present. Ultrastructural immunocytochemical studies are ongoing to investigate a possible interaction between biglycan and thick collagen fibrils in the endometrium in mice. Decorin-, fibromodulin-, lumican- and biglycan-null mice are all fertile, but more detailed characterization of their respective reproductive phenotypes is required, together 
with studies of the effects of SLRP gene ablation on fibril morphology.

As decorin has anti-proliferative activity, its loss at a time when stromal cells are passing through a round of DNA synthesis in preparation for decidualization (Tong and Pollard, 2002) is of likely functional significance. Whether decorin-bound TGF- $\beta$ is released from sites in the ECM during this process of remodelling remains to be established. The principle that alterations to uterine ECM are required before decidual differentiation is already established, for example, by the demonstration that collagen $\mathrm{VI}$ is lost from stromal tissue before the onset of expression of decidual markers such as desmin (Mulholland et al., 1992; Dziadek et al., 1995; Mylona et al., 1995).

The mechanism of loss of decorin and lumican before decidualization requires elucidation. An inflammatory cell infiltrate appears in the endometrium at day 1 after mating, most notably in the subepithelial stroma (Brandon 1993, 1995; McMaster et al., 1993; Pollard et al., 1998; Robertson et al., 2000), partly as a result of stimulation by TGF- $\beta$ in seminal plasma (Robertson et al., 1998; Tremellen et al., 1998). The predominant cells are macrophages, neutrophils and eosinophils, which are all capable of producing a repertoire of secretory enzymes (including matrix metalloproteinases) that degrade components of the ECM. Mast cells are also present. The spatiotemporal course of the disapprearance of decorin and lumican, beginning at day 1 with their clearance from the subepithelial stroma, is consistent with the possibility of breakdown by products of inflammatory cells accumulating in this area. It has been shown that administration of oestrogen to castrated mice stimulates deposition of decorin in the endometrial stroma (T. M. T. Zorn and S. San Martin, unpublished). The slight increase of decorin observed in the superficial stroma on day 4 of pregnancy in the present study may result from the peak of nidatory oestrogen on this day.

In summary, the present study has established that remodelling of ECM during decidualization includes alterations in the expression and distribution of four members of the SLRP family. Close correlations with changes in collagen fibril morphology indicate a functional association between these proteoglycans and collagen deposition. In addition, it is likely that decidual proteoglycans influence cell growth and differentiation in the pregnant uterus directly and by modulating local growth factor availability.

This study was carried out as partial fulfilment of a $\mathrm{PhD}$ degree by S. San Martin (advisor: T. M. T. Zorn) and was supported by a fellowship from FAPESP (00/04078-4 and 01/12283-0). M. SotoSuazo is supported by the Program of Academic Advancement of the University of Santiago de Chile, Chile and by a fellowship from $\mathrm{CNPq}$, Brazil. The authors are grateful to L. Fisher (National Institute of Dental and Craniofacial Research, NIH, Bethesda, USA) and A. Oldberg (University of Lund, Sweden) for antibodies.

\section{References}

Abrahamsohn PA and Zorn TMT (1993) Implantation and decidualisation in rodents Journal of Experimental Zoology 266 603-628

Abrahamsohn PA, Zorn TMT and Oliveira S (2002) Decidua in rodents. In The Endometrium pp 279-293 Eds SR Glasser, JD Aplin, LC Giudice and S Tabibzadeh. Taylor and Francis, London

Alberto-Rincon MC, Zorn TMT and Abrahamsohn PA (1989) Diameter increase of collagen fibrils of the mouse endometrium during decidualisation American Journal of Anatomy 186 417-429

Ameye L, Aria D, Jepsen K, Oldberg A, Xu T and Young MF (2002) Abnormal collagen fibrils in tendons of biglycan/fibromodulin-deficient mice lead to gait impairment, ectopic ossification, and osteoarthritis FASEB Journal 16 673-680

Antonsson P, Heinegard D and Oldberg A (1991) Post-translational modifications of fibromodulin Journal of Biological Chemistry 266 16859-16861

Aplin JD (2002) Endometrial extracellular matrix. In The Endometrium pp 294-307 Eds SR Glasser, JD Aplin, LC Giudice and S Tabibzadeh. Taylor and Francis, London

Aplin JD and Jones CJP (1989) Extracellular matrix in endometrium and decidua. In Placenta as a Model and Source pp 115-128 Eds O Genbacev, A Klopper and R Beaconsfield. Plenum Press, New York

Aplin JD, Charlton AK and Ayad S (1988) An immunohistochemical study of human endometrial extracellular matrix during the menstrual cycle and first trimester of pregnancy Cell Tissue Research 253235 240

Bijovsky AT, Zorn TMT and Abrahamsohn PA (1992) Remodeling of the mouse endometrial stroma during the preimplantation period Acta Anatomica 144 231-234

Birk DE, Fitch JM, Babiarz JP, Doane KJ and Linsenmayer TF (1990) Collagen fibrillogenesis in vitro: interaction of types I and $\mathrm{V}$ collagen regulates fibril diameter Journal of Cell Science 95 649-657

Blochberger TC, Cornuet PK and Hassell JR (1992) Isolation and partial characterization of lumican and decorin from adult chicken corneas. A keratan sulfate-containing isoform of decorin is developmentally regulated Journal of Biological Chemistry 267 20 613-20 619

Brandon JM (1993) Leucocyte distribution in the uterus during the preimplantation period of pregnancy and phagocyte recruitment to sites of blastocyst attachment in mice Journal of Reproduction and Fertility 98 567-576

Brandon JM (1995) Macrophage distribution in decidual tissue from early implantation to the periparturient period in mice as defined by the macrophage differentiation antigens F4/80, macrosialin and the type 3 complement receptor Journal of Reproduction and Fertility $\mathbf{1 0 3}$ 9-16

Chakravarti S, Magnuson T, Lass J, Jepsen K, LaMantia C and Carroll H (1998) Lumican regulates collagen fibril assembly: skin fragility and corneal opacity in the absence of lumican Journal of Cell Biology 141 1277-1286

Church HJ, Vicovac Lj, Williams JDL, Hey NA and Aplin JD (1996) Human decidual cells express laminins 2 and 4 Laboratory Investigation $\mathbf{7 4}$ $21-32$

Comper WD and Veis A (1977) The mechanism of nucleation for in vitro collagen fibrils formation Biopolymers 16 2113-2131

Danielson K, Baribault H, Holmes D, Graham H, Kadler K and lozzo R (1997) Targeted disruption of decorin leads to abnormal collagen fibril morphology and skin fragility Journal of Cell Biology 136729 749

De Feo VJ (1967) Decidualisation. In Cellular Biology of the Uterus pp 191-290 Ed. RM Wynn. Appleton-Century-Crofts, New York

De Luca A, Santra M, Baldi A, Giordano A and lozzo RV (1996) Decorininduced growth suppression is associated with up-regulation of p21, an inhibitor of cyclin-dependent kinase Journal of Biological Chemistry 271 18961-18965

Dunlevy JR, Neame PJ, Vergnes JP and Hassell JR (1998) Identification of the $\mathrm{N}$-linked oligosaccharide sites in chick corneal lumican and keratocan that receive keratan sulfate Journal of Biological Chemistry 2739615 9621 
Dziadek M, Darling P, Zhang RZ, Pan TC, Tillet E, Timpl R and Chu ML (1995) Expression of collagen alpha 1(VI), alpha 2(VI), and alpha 3(VI) chains in the pregnant mouse uterus Biology of Reproduction 52 885894

Ezura Y, Chakravarti S, Oldberg A, Chervoneva I and Birk DE (2000) Differential expression of lumican and fibromodulin regulate collagen fibrillogenesis in developing mouse tendons Journal of Cell Biology 151 779-787

Finn CA (1977) The implantation reaction. In Biology of the Uterus pp 245-308 Ed. RM Wynn. Plenum Press, New York

Finn CA and McLaren A (1967) A study of the early stages of implantation in mice Journal of Reproduction and Fertility 13 259-267

Fisher LW, Termine JD and Young MF (1989) Deduced protein sequence of bone small proteoglycan I (biglycan) shows homology with proteoglycan II (decorin) and several non-connective tissue proteins in a variety of species Journal of Biological Chemistry 264 45714576

Fisher LW, Stubbs JT 3rd and Young MF (1995) Antisera and cDNA probes to human and certain animal model bone matrix noncollagenous proteins Acta Orthopaedica Scandinavica Supplementum 266 61-65

Greca CD, Nader HB, Dietrich CP, Abrahamsohn PA and Zorn TMT (2000) Ultrastructural cytochemical characterization of collagen-associated proteoglycans in the endometrium of mice Anatomical Record 259413 423

Greca CP, Abrahamsohn PA and Zorn TMT (1998) Ultrastructural cytochemical study of proteoglycans in the endometrium of pregnant mice using cationic dyes Tissue and Cell 30 304-311

Hausser H, Groning A, Hasilik A, Schonherr E and Kresse H (1994) Selective inactivity of TGF-beta/decorin complexes FEBS Letters 353 243-245

Hedbom E and Heinegard D (1989) Interaction of a 59-kDa connective tissue matrix protein with collagen I and collagen II Journal of Biological Chemistry 264 6898-6905

Hocking AM, Shinomura T and McQuillan DJ (1998) Leucine-rich repeat glycoproteins of the extracellular matrix Matrix Biology 17 1-19

Iozzo RV (1997) The family of small leucine-rich proteoglycans: key regulators of matrix assembly and cellular growth Critical Reviews in Biochemistry and Molecular Biology 32 141-174

Iozzo RV (1999) The biology of the small leucine-rich proteoglycans. Functional network of interactive proteins Journal of Biological Chemistry $27418843-18846$

Kadler KE, Holmes DF, Trotter JA and Chapman JA (1996) Collagen fibril formation Biochemical Journal 316 1-11

Kolb M, Margetts PJ, Sime PJ and Gauldie J (2001) Proteoglycans decorin and biglycan differentially modulate TGF-beta-mediated fibrotic responses in the lung American Journal of Physiology. Lung Cellular and Molecular Physiology 280 L1327-L1334

Krusius T and Ruoslahti E (1986) Primary structure of an extracellular matrix proteoglycan core protein deduced from cloned cDNA Proceedings National Academy of Sciences USA 83 7683-7687

Lysiak JJ, Hunt J, Pringle GA and Lala PK (1995) Localization of transforming growth factor beta and its natural inhibitor decorin in the human placenta and decidua throughout gestation Placenta 16 221-231

McMaster MT, Dey SK and Andrews GK (1993) Association of monocytes and neutrophils with early events of blastocyst implantation in mice Journal of Reproduction and Fertility 99 561-569

Miosge N, Flachsbart K, Goetz W, Schultz W, Kresse H and Herken R (1994) Light and electron microscopical immunohistochemical localization of the small proteoglycan core proteins decorin and biglycan in human knee joint cartilage Histochemical Journal 26939 945

Mosacatello DK, Santra M, Mann DM, McQuillan DJ, Wong AJ and lozzo RV (1998) Decorin suppresses tumor cell growth by activating the epidermal growth factor receptor Journal of Clinical Investigation 101 406-412

Mulholland J, Aplin JD, Ayad S, Hong L and Glasser SR (1992) Loss of collagen type IV from rat endometrial stroma during decidualisation Biology of Reproduction 46 1136-1143
Mylona P, Kielty CM, Hoyland J and Aplin JD (1995) Expression of type V collagen in human endometrium and decidua Journal of Reproduction and Fertility 103 159-167

Oliveira SF, Abrahamsohn PA, Nagata T and Zorn TMT (1995) Incorporation of $3 \mathrm{H}$-amino acids by endometrial stromal cells during decidualisation in the mouse. A radioautographical study Cellular and Molecular Biology 41 107-116

Parr MB and Parr EL (1989) The implantation reaction. In Biology of the Uterus pp 233-277 Eds RM Wynn and WP Jollie. Plenum Publishing Corporation, New York

Pollard JW, Lin EY and Zhu L (1998) Complexity in uterine macrophage responses to cytokines in mice Biology of Reproduction 58 14691475

Psychoyos A (1960) La réaction déciduale est précédée de modifications précoces de la perméabilité capillaire de l'utérus Comptes rendus des seances de la Societe de Biologie et de ses filiales 1541384

Rada JA, Cornuet PK and Hassell JR (1993) Regulation of corneal collagen fibrillogenesis in vitro by corneal proteoglycan (lumican and decorin) core proteins Experimental Eye Research 56 635-648

Reinius S (1967) Ultrastructural of blastocyst attachment in the mouse Zeitschrift fur Zellforschung und mikroskopische Anatomie 77 257266

Robertson SA, Allanson M and Mau VJ (1998) Molecular regulation of uterine leukocyte recruitment during early pregnancy in the mouse Trophoblast Research 11 101-119

Robertson SA, Mau VJ, Young IG and Matthaei KI (2000) Uterine eosinophils and reproductive performance in interleukin 5-deficient mice Journal of Reproduction and Fertility 120 423-432

Santra M, Mann DM, Mercer EW, Skorski T, Calabretta B and lozzo RV (1997) Ectopic expression of decorin protein core causes a generalized growth suppression in neoplastic cells of various histogenetic origin and requires endogenous p21, an inhibitor of cyclin-dependt kinase Journal of Clinical Investigation 100 149-157

Schaefer L, Macakova K, Raslik I et al. (2002) Absence of decorin adversely influences tubulointerstitial fibrosis of the obstructed kidney by enhanced apoptosis and increased inflammatory reaction American Journal of Pathology 160 1181-1191

Schonherr E, Witsch-Prehm P, Harrach B, Robenek H, Rauterberg J and Kresse H (1995) Interaction of biglycan with type I collagen Journal of Biological Chemistry $2702776-2783$

Scott JE (1996) Proteodermatan and proteokeratan sulfate (decorin, lumican/fibromodulin) proteins are horseshoe shaped. Implications for their interactions with collagen Biochemistry 35 8795-8799

Svensson L, Aszódis A, Reinholt FP, Fassler R, Heinegard D and Oldberg A (1999) Fibromodulin-null mice have abnormal collagen fibrils, tissue, organization, and altered deposition in tendon Journal of Biological Chemistry 274 9636-9647

Tenorio DMH and Zorn TMT (1998) Endometrium of mouse during preimplantation period: morphological and immunohistochemical study 5th Brazilian Symposium on Extracellular Matrix Rio de Janeiro, Brazil

Tong W and Pollard JW (2002) Female sex steroid hormone regulation of cell proliferation in the endometrium. In The Endometrium pp 94-109 Eds SR Glasser, JD Aplin, LC Giudice and S Tabibzadeh. Taylor and Francis, London

Trelstad RL and Silver FH (1981) Matrix assembly. In Cell Biology of Extracellular Matrix pp 179-215 Ed. D Hay. Plenum Press, New York

Tremellen KP, Seamark RF and Robertson SA (1998) Seminal transforming growth factor beta 1 stimulates granulocyte-macrophage colonystimulating factor production and inflammatory cell recruitment in the murine uterus Biology of Reproduction 58 1217-1225

Uldbjerg $\mathbf{N}$ and Danielsen CC (1988) A study of the interaction in vitro between type I collagen and small dermatan sulphate proteoglycan Biochemical Journal 251 643-648

Vogel KG and Trotter JA (1987) The effect of proteoglycans on the morphology of collagen fibrils formed in vitro. Collagen and Related Research 7 105-114 
Vogel KG, Paulsson M and Heinegard D (1984) Specific inhibition of type I and type II collagen fibrillogenesis by the small proteoglycan of tendon Biochemical Journal 223 587-597

Williams BR, Gelman RA, Poppke DC and Piez KA (1978) Collagen fribril formation. Optimal in vitro conditions and preliminary kinetic results Journal of Biological Chemistry 253 6578-6585

Xu T, Bianco P, Fisher L et al. (1998) Targeted disruption of the biglycan gene leads to an osteoporosis-like phenotype in mice Nature Genetics 20 78-81
Zorn TMT, Bevilacqua EM and Abrahamsohn PA (1986) Collagen remodeling during decidualisation in the mouse Cell Tissue Research 244 443-448

Received 6 August 2002.

First decision 18 October 2002.

Revised manuscript received 19 November 2002.

Accepted 26 November 2002 